\title{
REFORMA EDUCATIVA A PARTIR DOS ANOS 1990: IMPLEMENTAÇÃO NA AMÉRICA LATINA E CARIBE, E PARTICULARIDADES BRASILEIRAS
}

\author{
L. L. S. SILVA' e M. A. AZEVEDO \\ ${ }^{1,2}$ Instituto Federal do Rio Grande do Norte \\ E-mail: lenina.natal@digi.com.br ${ }^{1}$, marcio.azev@yahoo.com.br ${ }^{2}$
}

Artigo submetido em maio/2012 e aceito em maio/2012

\section{RESUMO}

Reflete-se acerca de alguns pontos e contrapontos da reforma educativa implantada na América Latina e Caribe, nos anos 1990, enfocando-se as particularidades da efetivação dessa reforma no Brasil. Trata-se de um estudo teórico que prioriza a literatura que versa sobre os pressupostos que fundamentam a economia global e informacional norteadora das reformas no plano político e influenciadoras das transformações sociais em escalas: local, regional, nacional e internacional, bem como da reforma educativa em discussão. Observa-se que, praticamente todos os países da América Latina e Caribe impulsionaram ações e esforços na direção de reformas educativas. No caso brasileiro os estudos enfatizam que essas reformas se encaminharam para a reorganização institucional, a descentralização da gestão administrativa, financeira e pedagógica e para o fortalecimento da autonomia das escolas. Essas sinalizaram, ainda, para uma política de municipalização com transferência de responsabilidades da União para os municípios e para a desarticulação do ensino médio integrado, respaldada pelo Projeto de Lei no 1.603/96 e pelo Decreto no 2.208/97, no âmbito da educação profissional.

PALAVRAS-CHAVE: Reforma educativa, Economia Global e Informacional, Educação Profissional.

\section{REFORMA EDUCATIVA EN LOS AÑOS DE 1990: IMPLEMENTACIÓN EN AMÉRICA LATINA Y CARIBE, Y PARTICULARIDADES BRASILEÑAS}

\section{RESUMEN}

Reflejase acerca algunos puntos y contrapuntos de La reforma educativa implantadas en América Latina y Caribe en los años de 1990, planteándose las particularidades de La efectuación de esa reforma en Brasil. Tratase de un estudio teórico que prioriza La literatura que versa acerca los presupuestos que fundamentan La economía global e informacional orientadora de las reformas en El plan político e influenciadoras de los cambios sociales en escalas: local, regional, nacional e interaccional, bien como La reforma educativa en discusión. Observase que, en los últimos años del siglo $X X$, prácticamente todos los países de América Latina y Caribe impulsaron acciones y esfuerzos en La dirección de reformas educativas. En Brasil los estudios enfatizan que esas reformas se encaminen para La reorganización institucional, La descentralización de La gestión administrativa, financiera y pedagógica, y para El fortalecimiento de La autonomía de las escuelas. Estos señalizan aún para una política de municipalización con transferencias de responsabilidades de La unión para los municipios y para La desarticulación de La enseñanza media integrada, respaldada por El proyecto de ley n. 1603/96 y por El decreto n. 2208/97, en El ámbito de La educación profesional.

Palabras claves: Reforma educativa, economía global e informacional, educación profesional. 


\section{REFORMA EDUCATIVA A PARTIR DOS ANOS 1990: IMPLEMENTAÇÃO NA AMÉRICA LATINA E CARIBE, E PARTICULARIDADES BRASILEIRAS}

\section{NOTAS INTRODUTÓRIAS: ECONOMIA GLOBAL E INFORMACIONAL}

No século XX, foi consolidado o processo de industrialização e sistematização produtiva do capital, o que provocou significativas transformações na estrutura política e econômica dos países capitalistas. Esse cenário desencadeou-se efetivamente na segunda metade do século, representado por um longo período de expansão de pós-guerra que se estendeu de 1945 a 1975, tendo como base um conjunto de práticas de controle do trabalho, tecnologias, hábitos de consumo e configurações de poder (HARVEY, 1993). Dentre esses, o taylorismo/fordismo baseado na produção em massa de mercadorias e estruturado por meio de uma produção homogenizadora e amplamente verticalizada. A produção expandiu-se em vários setores: inicialmente, na indústria automobilística nos EUA, e, em seguida, para quase todos os principais países capitalistas, com incidência sobre significativa parte do setor de serviços (ANTUNES, 2000).

Contudo, com o primeiro choque do petróleo $^{1}$, os preços foram elevados o que conduziu a economia para novas configurações políticas e sociais (HARVEY, 1993), notadamente, a partir de 1973, quando o modelo fordista ${ }^{2}$ entrou em uma crise decorrente de um cenário de profunda recessão econômica. Nesse momento foi instituído um novo modelo: o de acumulação flexível dos processos de trabalho. Nesse sentido, os estudos de Harvey (1993, p. 140) mostram que esse processo foi caracterizado, essencialmente, pelo "[...] surgimento de setores de produção inteiramente novos, novas maneiras de fornecimento de serviços financeiros, novos mercados e, sobretudo, taxas altamente intensificadas de inovação comercial, tecnológica e organizacional [...]".

Os estudos de Antunes (2000, p. 119) apontam ainda que, o pós-fordismo, é uma conseqüência da crise da social-democracia e dos modos fordistas de regulação, e que, seria caracterizado a partir dos anos 1990, por "[...] novos modos de regulação, adequados a novas formas de produção, que definem tanto os limites como as oportunidades para as novas estratégias políticas. [...]". Vemos, pois, que o sistema capitalista dinamiza e reestrutura a sua base material de produção, à medida que o mercado vai se complexificando.

Nesse particular, identificamos que as últimas décadas do século XX, especialmente os anos 1990, foram marcadas pela globalização da economia mundial, selando também um processo emergente de evolução tecnológica, cuja base organizou-se em torno da informação, compreendida como a revolução tecnológica ${ }^{3}$, inaugurando, dessa maneira, um processo no qual a mente humana torna-se fonte direta de produção, como enfatizam os estudos de Castells (1999, p. 52), ao afirmar que:

\footnotetext{
${ }^{1}$ Segundo Xavier; Ribeiro; Noronha (1994), essa crise é resultado da manifestação dos países árabes membros da OPEP, que decidiram suspender as exportações, em sinal de protesto ao apoio dado a Israel por países do Ocidente no conflito do Oriente Médio.

${ }^{2}$ Essa crise foi desencadeada por diferentes fatores, como: a) econômicos: recuperação da Europa Ocidental e do Japão; queda da produtividade e da lucratividade corporativa depois de 1966, nos EUA; falência técnica da cidade de Nova lorque (1975); b) sociais: divisão social do trabalho; desqualificação do trabalhador; altos índices de desemprego; greves acentuadas e problemas trabalhistas (1965-1973); c) políticas: a formação do eurodólar e a contração do crédito no período 1966-1967; industrialização fordista competitiva em ambientes internacionais novos; aumento do preço do petróleo (OPEP) - 1973; embargo às exportações do petróleo para o Ocidente (1973); d) ideológicas: embate à hegemonia americana; crise e mudança paradigmática dos movimentos trabalhistas e sindicais (HARVEY, 1993).

${ }^{3}$ Ao referir-se a essa revolução, Schaff (1995, p. 43-44) ressalta que temos incluídos em um contexto denominado de a "sociedade da informática". Para Santos (2004, p. 23), “[...] produziu-se um sistema de técnicas da informação, que 
[...] as novas tecnologias da informação difundiram-se pelo globo com a velocidade da luz em menos de duas décadas, entre meados dos anos 70 e 90, por meio de uma lógica que, a meu ver, é a característica dessa revolução tecnológica: a aplicação imediata no próprio desenvolvimento da tecnologia gerada, conectando o mundo através da tecnologia da informação. [...].

Entretanto, Castells reconhece que essa propagação informacional é seletiva e excludente socialmente, pois milhares de sujeitos são privados de seu acesso funcional, como os moradores de favelas e áreas rurais do mundo inteiro. Na verdade, é o capital que detém, proporciona e/ou limita o acesso à informação e às novas tecnologias para alicerçar o seu sistema econômico e ideológico. Nessa perspectiva, os estudos de Santos (2004, p. 28) mostram que:

[...] a informação instantânea e globalizada por enquanto não é generalizada e veraz porque atualmente intermediada pelas grandes empresas da informação. [...] A história é comandada pelos grandes atores desse tempo real, que são, ao mesmo tempo, os donos da velocidade e os autores do discurso ideológico. [...] Fisicamente, isto é, potencialmente, ele existe para todos. Mas efetivamente, isto é, socialmente, ele é excludente e assegura exclusividades, ou pelo menos, privilégios de uso.

Com o mesmo entendimento, os estudos de Schaff (1995) vão destacar que a sociedade informacional e global desloca-se da possibilidade de um progresso científico a serviço de toda humanidade, como um bem comum, para atender aos preceitos que interessam ao capital. Isso define inclusive, um modelo de política que se submete ao mercado, no qual os grandes atores são as empresas globais, que determinam um quadro obsoleto para os que estão à margem do poder, conforme proposições de Santos (2004). Com a emergência dessa nova realidade econômica, que redimensiona o papel do Estado-Nação, o mercado global articula novas formas de poder, no qual o "nacional, o regional e o local são colocados a serviço do novo modelo econômico global transnacional e transcultural [...]" (GANBOA, 2001, p. 96). Representa desse modo, um poderoso Proto-Estado-Nação ${ }^{4}$. Segundo essa premissa, percebemos que se trata do predomínio de estruturas mundiais de poder que, na visão de lanni $(2002$, p. 226) são:

[...] as corporações transnacionais, o Grupo dos 7 (G7), a Organização para a Cooperação Econômica e o Desenvolvimento (OECD), o Fundo Monetário Internacional (FMI), o Banco Mundial ou o Banco Internacional de Reconstrução e Desenvolvimento (BIRD), entre outras, que operam de cima para baixo, à revelia dos povos e coletividades que compõem a maioria da população mundial.

Acerca da composição do Proto-Estado-Global, destacamos o papel da OMC Organização Mundial do Comércio (OMC), do Fundo Monetário Internacional (FMI) e do Banco Mundial. Estes além de negociarem empréstimos em grande parte do mundo, desempenham o papel estratégico de orientação e de reestruturação socioeconômica dos países em desenvolvimento, por meio de políticas de ajuste estrutural. Em estudos anteriores ao referido antes, lanni (1993) ressalta que

passaram a exercer um papel de elo entre as demais, unindo-as e assegurando ao novo sistema técnico uma presença planetária [...] Na história da humanidade é a primeira vez que tal conjunto de técnicas envolve o planeta como um todo e faz sentir, instantaneamente, sua presença [...]".

${ }^{4}$ Os estudos de Ganboa (2001) mostram que esse poderoso Proto-Estado-Global é uma reconfiguração de poder das classes dominantes, como as instituições que são descritas por Ianni (2002). 
essas instituições, como o FMI e o Banco Mundial, "[...] têm sido capazes de induzir, bloquear ou reorientar políticas econômicas nacionais [...]" (IANNI, 1993, p. 130), a exemplo do que aconteceu no Brasil a partir dos anos de 1990, inclusive, na educação.

Reconhecidamente, a inserção do continente latino-americano nesse projeto de um Proto-Estado-Global exigiu ajustes fiscais e a superação de natureza socioeconômica, política e educacional, levando os países a efetivarem reformas estruturais, vislumbrando um Estado mínimo do ponto de vista social, mais forte, em relação aos interesses do capital, utilizando-se das ferramentas da economia informacional. Nessa direção, os estudos de Dupas (2007, 19-20) corroboram informando que: "ajudado pelas novas tecnologias da informação, que oferecem possibilidades de encolher horizontes temporais e abolir as distâncias o poder do capital se amplia sem enfrentar diretamente as leis nacionais [...].

No delineamento desse Estado forte para o capital, identificamos que a sua atuação é redimensionada nos setores sociais, sobretudo, com os serviços públicos de saúde, educação e segurança, os quais seguem recomendações de uma política com enfoque neoliberal. No campo das superações, os estudos de Borón (2003) enfatizam que as reformas ${ }^{5}$ na América Latina giraram em torno de três eixos:

a) O desmantelamento do setor público, que, indo de encontro às tendências dos países do primeiro mundo, apresentou uma enorme ineficiência de gestão, fragmentando as suas ações governamentais a programas de governos inconsistentes e assistencialistas;

b) As condições desfavoráveis de competitividade e crescimento dos Estados, provocadas pela abertura, liberação e desregulação sem precedentes para empresas e mercados mais fortes;

c) Os desajustes sociais, conseqüência do descaso governamental dos Estados com relação a áreas críticas de sua competência. De um lado, a dificuldade de implementação de políticas sociais consistentes e, de outro, a negligência ao propor e/ou efetivar a sua política econômica, sem consistência, o que gerou a desconfiança dos mercados credores.

Diante dessa realidade, foram propostas $10+1$ ferramentas de igualdade social ${ }^{6}$, objetivando sair do círculo vicioso e empunhando concretamente ações que reduzissem a pobreza e as iniqüidades sociais, sem comprometer o crescimento e a eficiência econômica (BORÓN, 2001). Por meio de uma disciplina fiscal, moderariam os câmbios e as recessões, a criação de redes de seguridade social, a oferta de escolas para todos, a efetivação de uma política de arrecadação fiscal, principalmente, entre os ricos, a fim de incentivar pequenos negócios, a proteção dos direitos trabalhistas, a superação da discriminação socioeconômica, principalmente entre índios e negros, na reestruturação na política de distribuição de terras.

A ferramenta intitulada de mais um dá ênfase à cultura do consumo, e propõe que:

a) os países ricos reduzam o protecionismo aos seus mercados, permitindo que os países latino-americanos tenham acesso a estes;

\footnotetext{
${ }^{5}$ Borón (2003) prefere intitular de a las (mal) llamadas reformas del estado, ou seja, de contra-reformas do Estado, tendo em vista o seu caráter excludente e regressivo, o que só ratificou as desigualdades e os impedimentos de um efetivo desenvolvimento econômico e social.

${ }^{6}$ Indicadas para os governos reduzirem a pobreza e a iniqüidade social de seus países, sem comprometer a eficiência e o crescimento econômico.
} 
b) A instituição de uma política que incentive e gere emprego e renda formais;

c) A criação de sistemas de seguridade social, como fundos de pensão, a fim de reduzir a carga previdenciária dos Estados;

d) Incentivo e efetividade das privatizações;

e) Abertura ao comércio internacional, por meio de blocos econômicos, como o MERCOSUL (Mercado Comum do Sul). Os estudos de Borón (2003) mostram que iniciativas como essas apresentam-se como eixo de prioridades;

f) Executar a reforma do setor público, a fim de aumentar a eficiência e a competência gerencial dos Estados. Destacamos, nesse caso, a atenção que é dada à descentralização dos serviços públicos;

g) Melhoria da qualidade da educação básica (no caso brasileiro, a ênfase maior recai sobre o Ensino Fundamental) e um nítido incentivo à privatização do Ensino Superior;

Em face do exposto, o Banco Mundial tem se concentrado em estudos acerca do novo papel do Estado e em reformas frente a essa tendência e às suas proposições, incentivando a efetividade de realizações dessa natureza nos países da América Latina e Caribe.

Dentro desse cenário, a educação, que estrategicamente é condicionada aos interesses do mercado, vem enquadrando-se na redefinição de uma nova concepção de sociedade global e informacional - conduzida pelo Proto-Estado-Global -, adequando-se, assim, em seu caráter formador, aos interesses dominantes; tornando-se estereotipada e impeditiva. Isto porque, os sujeitos não se apropriam do saber necessário para a sua formação humana, como vem acontecendo na educação do campo. Trata-se, portanto, de uma educação que dá margem a uma nova concepção de formação de força de trabalho que prioriza a "formação técnica, desprezando o potencial humano para a criatividade e a produção científica” (GANBOA, 2001, p. 99).

Sendo assim, é com esse entendimento que nos propomos a refletir sobre alguns pontos e contrapontos da reforma educativa implantada na América Latina e Caribe, nos anos 1990, enfocando-se as particularidades da efetivação dessa reforma no Brasil. Trata-se de um estudo teórico que tem como proposta fundamental alicerçar análises de pesquisas em educação profissional, com base no contexto sociocultural e histórico-econômico priorizando a literatura que versa sobre os pressupostos que fundamentam a economia global e informacional. Esta entendida como norteadora das reformas educativas no plano político e influenciadoras das transformações sociais em escalas: local, regional, nacional e internacional, bem como da reforma educativa em discussão. De antemão, observamos que, praticamente todos os países da América Latina e Caribe impulsionaram ações e esforços na direção de reformas que atingiram o setor da educação. No caso do Brasil os estudos enfatizam que essas reformas se encaminharam para a reorganização institucional, a descentralização da gestão administrativa, financeira e pedagógica e para o fortalecimento da autonomia das escolas. Essas sinalizaram, ainda, para uma política de municipalização com transferência de responsabilidades da União para os municípios e em especial, para a desarticulação do ensino médio integrado, respaldada pelo Projeto de Lei no 1.603/96 e pelo Decreto no $2.208 / 97$, no âmbito da educação profissional.

\section{PONTOS E CONTRAPONTOS DA REFORMA EDUCATIVA NOS ANOS 1990: ALGUMAS REFLEXÕES SOBRE A AMÉRICA LATINA E CARIBE}


Em sua abordagem sobre o projeto educativo, Torres (2003) ressalta a influência do Banco Mundial sobre o caráter formador e estratégico da educação. Afirma Torres (2003, p. 125) que, nos últimos anos, ele tem ocupado o espaço "[...] tradicionalmente conferido à Organização das Nações Unidas para a Educação, a Ciência e a Cultura (UNESCO), a agência das Nações Unidas especializada em educação". A interferência dessa instituição financeira firma-se, dessa forma, como garantia de exeqüibilidade da formação educacional nos padrões definidos pelos interesses vigentes.

Ante o exposto, as perspectivas para a educação nos países da América Latina e Caribe apresentam-se de forma sombria na visão de Ganboa quando diz:

O ideário de "Mais e melhor educação para todos" parece ser uma frase em extinção na maioria dos países da América Latina, inseridos num mundo onde os computadores, a internet e a informação são os eixos por onde passam as transformações e as possibilidades dos sujeitos terem acesso a eles. [...] Na conjuntura atual, determinada pela globalização da economia e a escalada do Proto-Estado Global, os Estados nacionais dos países periféricos e, dentre eles, os da América Latina, entram em crise e com eles surgem perspectivas sombrias para a educação pública (GANBOA, 2001, p. 100-101).

Nessa referência, identificamos as razões de os países desse continente submeterem-se às reformas que foram realizadas na década de 1990, conforme mostraram os estudos de Borón (2003). Discutindo as políticas sociais e o neoliberalismo, Draibe (1998, p. 92), em seus estudos, sinaliza para a compreensão de que a superação das desigualdades socioeconômicas é uma necessidade e uma condição para a estabilidade política:

Mas a eliminação da pobreza, a diminuição dos graus mais gritantes de desigualdades e a ampliação do acesso das camadas desfavorecidas aos benefícios do crescimento econômico constituem também condição da estabilidade política. Em outros termos, a estabilidade dos ajustamentos estará comprometida se os piores desequilíbrios sociais não forem eliminados, antes mesmo de se transformarem em desequilíbrios políticos (grifo da autora).

Corroborando a análise de Draibe, entendemos que o novo cenário mundial que vem se desenhando requer a capacidade dos países para desenvolverem mecanismos econômicos e estratégias políticas, capazes de enfrentar a competitividade internacional e a América Latina e o Caribe não estão isentos, desse exercício. Isso implica em desenvolver um potencial científicotecnológico capaz de competir no contexto da economia global e informacional, o que está longe de acontecer, como mostram os estudos de Ganboa (2001) e Santos (2004).

Nesse contexto específico da América Latina e do Caribe, os estudos de Gajardo (1999) ressaltam que, para ocorrerem os ajustes, e necessário desenvolver estratégias que permitam a formação de uma cidadania moderna, vinculada à competitividade dos países, abertura à democracia e à equidade. Pois, apesar dos avanços no contexto das reformas educativas em alguns países do continente latino-americano, como o Brasil, essas não corresponderam, satisfatoriamente, nem para o êxito econômico nem para o combate aos desajustes e às desigualdades sociais, tampouco para a superação da pobreza e para a melhoria da qualidade de vida de parte significativa da população. 
No caso brasileiro, os desequilíbrios e as desigualdades sociais são percebidos, claramente, na trajetória de sucessivas gestões no âmbito federal. A implementação de políticas, planos e programas de governo caracterizam-se por ações fragmentadas, descontinuadas e superpostas, sem que se alterem as condições estruturais ou mesmo a infra-estrutura com políticas de saneamento básico nas áreas de periferias urbanas, salvo as melhorias de alguns índices, como o da mortalidade infantil.

Analisando os estudos de Gajardo (1999), identificamos, também, que a Conferência Mundial de Educação Para Todos, em Jomtien (1990), proposta da CEPAL e da UNESCO (1992), acena para diversos compromissos firmados com o Banco Mundial e o Banco Interamericano de Desenvolvimento (BID). Nela, estão explícitas orientações aos países da América Latina, para que desenvolvam, efetivamente, políticas educacionais para atender às perspectivas do desenvolvimento socioeconômico no atual estágio de financeirização do capitalismo. Essa proposta de educação gerida por formas democráticas de participação no âmbito educacional pretendia responder aos desafios impostos pela economia global e informacional.

Nesse particular, o Banco Mundial definiu algumas metas, dentre as quais, a apresentação de resultados, o fortalecimento da autonomia escolar e a inovação na sua capacidade gerencial, bem como a capacitação de professores à luz de parâmetros técnicos decorrentes daqueles que orientam a economia. No período de 1991 a 1995, destacamos três reuniões ${ }^{7}$, realizadas entre o Banco Mundial e os Ministros da Educação de países da América Latina e do Caribe, nas quais se firmaram os principais acordos da reforma educativa.

No PROMEDLAC (Reuniões dos Ministros de Educação da América Latina e Caribe) IV, realizado em Quito/Equador (1991), estabeleceram-se compromissos no sentido de investir na formação de recursos humanos e fortalecer iniciativas sociais; promover o desenvolvimento educativo concernente aos desafios do mercado, da equidade social e da democratização política; executar mudanças nos processos de gestão da educação, com ênfase na administração e no planejamento; desenvolver mecanismos e estratégias que proporcionassem a integração de diversos setores, a fim de compartilhar as responsabilidades com a educação; e formular novos currículos, a fim de atender aos princípios básicos de aprendizagens, estabelecidos em Jomtien (1990), para tornar a prática pedagógica das escolas mais significativa.

Em Santiago/Chile (1993), na reunião do PROMEDLAC V, os Ministros da Educação acordaram em destinar mais recursos e melhorar a sua aplicação à educação; promover a modernização da gestão educacional, a profissionalização e a melhoria do funcionamento das escolas; priorizar e dar qualidade à educação básica, inclusive, nos processos de ensinoaprendizagem; investir na educação de jovens e adultos; e envolver os meios de comunicação no processo educacional, como agentes educativos.

Na reunião de Kingston/Jamaica (1995), o PROMEDLAC VI discutiu a agenda intitulada de transformação educativa. Desse modo, estabeleceram-se mecanismos de controle e de medição para acompanhar e comparar os níveis de competência e de indicadores da evolução do

\footnotetext{
7 Reuniões do PROMEDLAC (GAJARDO, 1999). Em março de 2001, ocorreu a última reunião, isto é, o PROMEDLAC VII, em Cochabamba. Nesse evento, as instituições promotoras e os participantes analisaram os resultados e a evolução dos 20 anos do projeto principal de educação na América Latina e Caribe, os desafios e perspectivas em âmbito político, social, econômico e cultura, nos quais se desenvolveria a educação na região no período de 2001-2006, bem como foram feitas recomendações sobre as políticas de educação para o início do século XXI.
} 
desempenho das escolas, bem como utilizar essas informações para melhorar a qualidade da educação. Discutiram, ainda, ações que propiciassem a valorização dos docentes e, assim, o seu desempenho funcional.

Apesar de os acordos enfatizarem a educação em um contexto mais amplo, as atenções para as ações da reforma educativa voltaram-se à Educação Básica e, no Brasil, especificamente, ao Ensino Fundamental. As diversas estratégias, programas e projetos que empunhavam as reformas educativas, a partir dos anos de 1990, concentraram-se em quatro eixos: a) gestão; b) qualidade e equidade; c) profissionalização docente; d) financiamento, como apontam os estudos de Gajardo (1999).

\section{REFLEXÕES ACERCA DAS PARTICULARIDADES DO BRASIL E A REFORMA EDUCATIVA NOS ANOS 1990}

Nos últimos anos, praticamente todos os países da América Latina e Caribe vêm impulsionando ações e esforços na direção da transformação educativa. No caso brasileiro, os estudos de Gajardo (1999) enfatizam que as reformas educativas encaminharam-se para a reorganização institucional e à descentralização da gestão administrativa, financeira e pedagógica, fortalecimento da autonomia das escolas, no que concerne às ações pedagógicas, curriculares e financeiras, de melhoria da qualidade e da equidade, à profissionalização docente $e$ a outros investimentos em educação.

Ressaltamos que, a política de municipalização da educação, com ênfase na transferência de responsabilidades da União para os municípios, levou à efetivação de vários programas federais, como a merenda escolar e o PDDE (Programa Dinheiro Direto na Escola) ${ }^{8}$. Essas e outras iniciativas do governo brasileiro acenavam com a possibilidade de constituir-se a autonomia financeira e pedagógica das escolas, assim como uma gestão "eficiente e eficaz" na utilização dos recursos. A eleição de diretores ${ }^{9}$ e a criação de Conselhos Escolares ${ }^{10}$ também constam na pauta das reformas educativas, como medidas plausíveis no que concerne à autonomia administrativa dos sistemas públicos de ensino no país.

Em decorrência da promulgação da Constituição Federal de 1988, foram elaboradas Constituições Estaduais e as Leis Orgânicas Municipais, um marco inovador no processo de democratização e autonomia das escolas brasileiras (GAJARDO, 1999). A Lei de Diretrizes e Bases

\footnotetext{
${ }^{8}$ O PDDE e outros programas do governo federal expressam um novo contexto da gestão educacional brasileira, onde há uma recentralização estratégica dos recursos, efetivada por meio da legislação vigente, onde se transferem recursos diretamente aos municípios e "[...] Não por coincidência, a escola passa a ser denominada de "Unidade Executora" (VIEIRA, 2004, p. 143). Segundo Libâneo (2003, p. 185), essas unidades executoras têm denominações distintas, como "Associações de Pais e Mestres, Caixa Escolar, Conselho Escolar, Cooperativa Escolar, Círculo de Pais e Mestres etc".

9 Modalidade de Gestão Democrática que vem sendo construída a partir da escolha pela comunidade escolar (professores, pais e alunos) dos diretores das organizações escolares, prática esta ainda pouco difundida em muitos municípios. No Estado do Rio Grande do Norte, por exemplo, em 2005, algumas escolas estaduais submeteram-se a esse processo.

${ }^{10}$ Analisando a função dos Conselhos de educação como o elo entre o Estado e a sociedade, estudos ressaltam que "[...] cabe, dentro de suas atribuições, a busca incessante do diálogo entre Estado e todos os setores implicados, interessados e compromissados com a qualidade da educação escolar em nosso país" (CURY, 2004, p. 60). 
da Educação Nacional - Lei no 9.394, de 22 de dezembro de 1996 - também compõe o campo normativo educacional da reforma educativa dos anos 1990.

Essas iniciativas marcaram a política educacional durante o governo de Fernando Henrique Cardoso, a partir de 1995, atendendo, dessa forma, aos quatro eixos da reforma educativa. No balanço dessas reformas, o Fundo de Fortalecimento da Escola (FUNDESCOLA), criado em 1998, é mencionado como um dos programas exitosos do governo brasileiro para a educação. Este Fundo é um programa do governo federal, desenvolvido em parceria com o Banco Mundial, e que se voltou para a formação continuada de professores de escolas rurais e áreas periféricas urbanas, visando à implantação de metodologias de ensino específicas, à aquisição de equipamentos e de mobiliário, bem como à construção e à reforma de prédios escolares.

Ainda com referência às iniciativas do Brasil frente às mudanças no quadro educativo, identificamos que o TELECURSO $2000^{11}$, programa de iniciativa da Fundação Roberto Marinho, também foi avaliado pelo Banco Mundial como experiência exitosa no contexto da reforma brasileira, sendo uma estratégia inovadora e possível de ser ampliada (GAJARDO, 1999), atendendo, assim, ao que tinha sido firmado no PROMEDLAC V, no Chile (1993).

Analisando os aspectos do financiamento da educação no contexto da reforma educativa, Gajardo (1999) também enfatiza que a criação do Fundo de Manutenção e Desenvolvimento do Ensino Fundamental e de Valorização do Magistério (FUNDEF) ${ }^{12}$, no Brasil, foi uma experiência bem-sucedida. Larrañaga apud Gajardo (1999) ressalta que esse fundo representa um marco e uma nova linha na política de financiamento da educação, representando um avanço no que concerne à valorização do magistério. Permitindo, ainda, efetivar e regularizar a situação funcional dos profissionais da educação, por meio de concursos públicos, aperfeiçoamento profissional em serviço, política salarial definida por meio de planos de cargos, carreira e salários, com incentivos decorrentes da produção e do aperfeiçoamento, a inclusão do planejamento e de atividades extra-escolares, como cursos e eventos, na carga-horária semanal, e melhoria das condições de trabalho.

Identificamos, também, que o Grupo de Institutos, Fundações e Empresas (GIFE) organização de cunho privado - investiu em programas sociais e educativos no Brasil. Dentre eles, destaca-se a Fundação Bradesco, o Instituto C\&A de Desenvolvimento Social, a Fundação Roberto Marinho, a Clemente Mariani e a Odebrecht, que desenvolveram, sobretudo, projetos educacionais de melhoria da rede de estabelecimentos públicos patrocinados pelo setor privado.

Nessa perspectiva, percebemos que no Brasil, a exemplo de outros países da América Latina, os governantes têm motivado diversas formas de colaboração das empresas com a educação. Nesse sentido, compreendemos que essas empresas participam e desenvolvem cada vez mais programas que contribuem para a melhoria da qualidade e equidade da educação e do ensino, tal como mostra Borón (2003). Na verdade, essas medidas convergem para o fomento de políticas de educação com caráter privatizante, em detrimento da educação pública.

Ao contrário do que proclamam esses organismos, as reformas educacionais na América Latina, na prática, não correspondem à superação das desigualdades sociais, mas, ao contrário,

\footnotetext{
${ }^{11}$ Dirige-se aos jovens e adultos que buscam completar os seus estudos (educação à distância).

${ }^{12}$ O FUNDEF foi criado pela Emenda Constitucional 14/96 e a Lei 9.424/96, de 24 de dezembro de 1996. Os recursos desse Fundo são aplicados na manutenção e desenvolvimento do Ensino Fundamental público, e na valorização de seu magistério. "Há autores que o consideram um fundinho, em razão do baixo valor do custo aluno/ano e da não participação da União em sua formação" (LIBÂNEO, 2003, p. 196).
} 
reforçaram as disparidades. Exemplo disso é o Brasil, onde sucessivos governos anunciaram mudanças, apresentando campanhas do tipo Acorda Brasil, no governo de Fernando Henrique Cardoso (1995), tentando traduzir a estratégia de mobilização social em busca de uma educação de qualidade, como ressaltam os estudos de Vieira (2000).

No cenário brasileiro, evidenciam-se políticas e/ou projetos educacionais que se propõem a promover a equidade social. Essa é uma perspectiva complexa que não seria possível de imediato, conforme sinalizam os estudos de Draibe (1998). Os avanços da economia global e informacional possibilitam o crescimento do mercado econômico, o avanço da ciência e da tecnologia, bem como as perpetuações das contradições e dos desajustes sociais, como ressaltam Castells (1999); Ganboa (2001); lanni (2002) e Santos (2004). Nessa direção, se os avanços tecnológicos prospectassem um amplo acesso, isso seria como observa Saviani (2008), a possibilidade de universalização da escola unitária a qual desenvolveria amplamente as potencialidades humanas (formação omnilateral). Porém, como também observa o autor, as relações sociais vigentes dificultam a generalização da produção baseada na ampliação do acesso às tecnologias avançadas como informa Dupas (2007).

No âmbito da educação profissional, os anos 1990 foram marcados pela criação do Sistema Nacional de Educação Tecnológica, visando à integração do país no desenvolvimento em escala global por meio de um processo de formação voltada às novas tecnologias. Segundo os estudos de Oliveira (2003), a ideia de educação tecnológica veiculadas em 1994 pelos documentos oficiais do Ministério da Educação, como os que discutem a legislação básica (BRASIL, 1994), os quais reduzem a concepção à mera aplicação prática e não à formação humana, ou aquela que articula e integra o ensino médio propedêutico à educação profissional. Como também observa Oliveira (2003), outros aspectos da reforma educativa promovida a partir dos anos de 1990 também podem ser mencionados na particularidade da educação profissional, como a desarticulação do ensino médio integrado, respaldada no Projeto de Lei n. 1.603/96 e, posteriormente, por meio do Decreto n. 2.208/97.

Finalizando, é preciso dizer, ainda, que estas reflexões de certo modo, perpassam as discussões acerca da política educacional no Continente Latino-Americano e no Caribe nos dias atuais, e que não são reflexões novas, pois carregam em seus fundamentos a história de reformas educativas que foram conduzidas por governos neoliberais, considerados por muitos estudiosos como conservadores. Sendo assim, aqui ficam expostas à produção de novos questionamentos; para atualização do debate sobre as questões que norteiam a educação e de igual modo sobre sua situação concreta nos países desse Continente, marcada por desigualdades, exclusão, fracassos e insucessos e, a partir dos anos 1990, pelo incremento da privatização da educação na Região.

\section{REFERÊNCIAS BIBLIOGRÁFICAS}

1. ANTUNES, Ricardo. Os sentidos do trabalho: ensaio sobre a afirmação e a negação do trabalho. São Paulo: BOMTEMPO, 2000.

2. OLIVEIRA, Maria Auxiliadora Monteiro. Políticas públicas para o ensino profissional: o processo de desmantelamento dos CEFETS. São Paulo: Papirus, 2003.

3. BORÓN, Atílio. El Estado y las "reformas del Estado orientadas al mercado". Los "desempeños" de la democracia en América Latina. In: KRAWCZYK, Nora Rut; WANDERLEY, Luiz Eduardo. 
América Latina: estado e reformas numa perspectiva comparada. São Paulo: Cortez, 2003. p. 1967.

4. CASTELLS, Manuel. A era da informação. São Paulo: Paz e Terra, 1999. vol. 1.

5. CURY, Carlos Roberto Jamil. Os conselhos de educação e a gestão dos sistemas. In: FERREIRA, Naura Syria Carapeto; AGUIAR, Márcia Ângela da S. (Orgs). Gestão da educação: perspectivas, impasses e compromissos. 4. ed. São Paulo: Cortez, 2004. p. 43-60.

6. DRAIBE, Sônia Miriam. As políticas Sociais e o neoliberalismo. Revista da USP, São Paulo, p. 86101, 1998.

7. DUPAS, Gilberto. Propriedade Intelectual: tensões entre a lógica do capital e os interesses sociais. In: VILLARES, Fábio (Org.) Propeiedade Intelectual: tensões entre o capital e a sociedade. São Paulo, Paz e Terra, 2007. p. 15-24.

8. GAJARDO, Marcela. Reformas educativas em América Latina: balance de uma década. OPREAL, [s.I.], n. 15. set. 1999.

9. GANBOA, Silvio Sanchez. A globalização e os desafios da Educação no limiar do novo século. In: LOMBARDI, José Claudinei. (Org.). Globalização, Pós-modernidade e Educação: história, filosofia e temas transversais. Campinas: Associados, 2001.

10. HARVEY, David. A condição pós-moderna. São Paulo: Loyola, 1993.

11. IANNI, Octavio. A era do globalismo. 7. ed. Rio de Janeiro: Civilização brasileira, 2002.

12. A sociedade global. 2. ed. Rio de Janeiro: Civilização Brasileira, 1993.

13. LIBÂNEO, José Carlos. et al. Educação Escolar: políticas, estrutura e organização. São Paulo: Cortez, 2003.

14. SANTOS, Milton. Por uma outra globalização: do pensamento único à consciência universal. 11. ed. Rio de Janeiro: Record, 2004.

15. SAVIANI, Dermeval. O trabalho como princípio educativo frente às novas tecnologias. In: FERRETTI, Celson João. et al. (Org.). Novas tecnologias, trabalho e educação. 10. ed. Petrópolis: Vozes, 2008.

16. SCHAFF, Adam. A sociedade da informática: as conseqüências sociais da segunda revolução industrial. Tradução: Carlos Eduardo Jordão Machado e Luis Arturo Obojes. 4. ed. São Paulo: Brasiliense, 1995.

17. TORRES, Rosa Maria. Melhorar a qualidade da educação básica? As estratégias do Banco Mundial. Tradução de Mónica Corullón. In: TOMMASI, Lívia De; WARDE, Jorge Mirian; HADDAD, Sérgio. (Orgs). 4. ed. São Paulo: Cortez, 2003. p. 125-186.

18. VIEIRA, Sofia Lerche. Função social, gestão e política educacional. In: FERREIRA, Naura Syria Carapeto; AGUIAR, Márcia Ângela da S. (Orgs). Gestão da educação: perspectivas, impasses e compromissos. 4. ed. São Paulo: Cortez, 2004.

19. XAVIER, Maria Elizabete Xavier; RIBEIRO, Maria Luisa; NORONHA, Olinda Maria. História da Educação: a escola no Brasil. São Paulo: FTD, 1994. 